Bull. Chem. Soc. Ethiop. 2013, 27(1), 95-104.

Printed in Ethiopia

ISSN 1011-3924

DOI: http://dx.doi.org/10.4314/bcse.v27i1.10

(c) 2013 Chemical Society of Ethiopia

\title{
SYNTHESIS AND CHARACTERIZATION OF THERMALLY STABLE POLY(AMIDE-IMIDE)-MONTMORILLONITE NANOCOMPOSITES BASED ON BIS(4-CARBOXYPHENYL)-N,N'-PYROMELLITIMIDE ACID
}

\author{
Khalil Faghihi $^{*}$, Ali Asghari ${ }^{2}$ and Mohsen Hajibeygi ${ }^{3}$ \\ ${ }^{1}$ Department of Chemistry, Faculty of Science, Arak University, Arak, 38156-8-8349, Iran \\ ${ }^{2}$ Department of Chemistry, Arak Branch, Islamic Azad University, Arak, Iran \\ ${ }^{3}$ Department of Chemistry, Varamin Pishva Branch, Islamic Azad University, Varamin, Iran
}

(Received May 10, 2011; revised November 28, 2012)

\begin{abstract}
Two new poly(amide-imide)-montmorillonite reinforced nanocomposites containing bis(4-carboxyphenyl)-N,N'-pyromellitimide acid moiety in the main chain were synthesized by a convenient solution intercalation technique. Poly(amide-imide) (PAI) as a source of polymer matrix was synthesized by the direct polycondensation reaction of bis(4-carboxyphenyl)-N,N'pyromellitimide acid with 4,4'-diamino diphenyl sulfone in the presence of triphenyl phosphite (TPP), $\mathrm{CaCl}_{2}$, pyridine and $\mathrm{N}$-methyl-2-pyrrolidone (NMP). Morphology and structure of the resulting PAI-nanocomposite films with 10 and $20 \%$ silicate particles were characterized by FT-IR spectroscopy, X-ray diffraction (XRD) and scanning electron microscopy (SEM). The effect of clay dispersion and the interaction between clay and polymeric chains on the properties of nanocomposites films were investigated by using UV-Vis spectroscopy, thermal gravimetry analysis (TGA) and water uptake measurements.
\end{abstract}

KEYWORDS: Bis(4-carboxyphenyl)-N,N'-pyromellitimide acid moiety, Poly(amide-imide)montmorillonite nanocomposite, Thermal properties

\section{INTRODUCTION}

Polymer-clay nanocomposites typically exhibited mechanical, thermal and gas barrier properties, which are superior to those of the corresponding pure polymers [1-9]. Unique properties of the nanocomposites are usually observed when the ultra fine silicate layers are homogenously dispersed throughout the polymer matrix at nanoscale. The uniform dispersion of silicate layers is usually desirable for maximum reinforcement of the materials. Due to the incompatibility of hydrophilic layered silicates and hydrophobic polymer matrix, the individual nanolayers are not easily separated and dispersed in many polymers. For this purpose, silicate layers are usually modified with an intercalating agent to obtain organically modified clay prior to use in nanocomposite formation $[10,11]$. Also aromatic polyimides are well recognized as a class of high performance materials due to their remarkable thermal and oxidative stabilities and excellent electrical and mechanical properties for long time periods of operation [12]. Unfortunately, strong interaction between polyimide chains and their rigid structure make them intractable. Poor thermoplastic fluidity and solubility are the major problems for wide application of polyimides. Thus, to overcome these processing problems various approaches have been carried out by incorporating flexible units such as - $\mathrm{NHCO}-,-\mathrm{O}_{-}$, and $-\mathrm{SO}_{2-}$, and some of which are commercialized [13-14]. Among them, poly(amide-imide) (PAI) is the most successful material, which combines the advantages of high-temperature stability and processability [15-22]. In this article two PAI-nanocomposite films with 10 and $20 \%$ silicate particles containing chiral bis(4-carboxyphenyl)-N,N'-pyromellitimide acid moiety in the main chain was prepared by using a convenient solution intercalation technique.

*Corresponding author. E-mail: k-faghihi@araku.ac.ir 


\section{EXPERIMENTAL}

\section{Materials}

Pyromellitic dianhydride, $p$-amino benzoicacid, 4,4'-diamino diphenyl sulfone, acetic acid, triphenyl phosphite (TPP), $\mathrm{CaCl}_{2}$, pyridine and $\mathrm{N}$-methyl-2-pyrrolidone (NMP), N,N-dimethyl formamide (DMF) were purchased from Merck Chemical Company and used without previous purification. Purified the organically-modified Cloisite ${ }^{\circledR} 20 \mathrm{~A}$ supplied by Southern Clay Products (TX), were used as polymer nanoreinforcement.

\section{Measurements}

${ }^{1}$ H-NMR spectra was recorded on a Bruker $300 \mathrm{MHz}$ instrument (Germany). Fourier transform infrared (FT-IR) spectra were recorded on Galaxy Series FT-IR 5000 spectrophotometer (England). UV-Vis spectra were recorded at $25{ }^{\circ} \mathrm{C}$ in the $300-800 \mathrm{~nm}$ spectral regions with a Perkin Elmer Lambda 15 spectrophotometer in NMP solution using cell lengths of $1 \mathrm{~cm}$. Thermogravimetric analysis and differential scanning calorimetry (TGA and DSC) data were taken on a Mettler TA4000 System under $\mathrm{N}_{2}$ atmosphere at a rate of $10{ }^{\circ} \mathrm{C} / \mathrm{min}$. The morphology and structure of nanocomposite film was investigated on Canbridge S260 scanning electron microscope (SEM) and Rigaku D - max CIII X-ray diffraction (XRD). Elemental analyses were taken on a Vario AV.

\section{Monomer synthesis}

A mixture of pyromellitic dianhydride $1(3.00 \mathrm{~g}, 13.70 \mathrm{mmol}), p$-amino benzoic acid 2 (3.76 g, $27.50 \mathrm{mmol}$ ) and $130 \mathrm{~mL}$ acetic acid with appropriate amounts of pyridine was stirred and mixture was refluxed at $120{ }^{\circ} \mathrm{C}$ for $12 \mathrm{~h}$ until the precipitate was formed, the precipitate was filtered off, washed thoroughly with water and dried to afford $4.52 \mathrm{~g}$ compound 3 (yield 72.1\%). M.p.: $310{ }^{\circ} \mathrm{C}$, FT-IR (KBr): 3500-2500, 3070, 1778, 1722, 1600-1580, 1422-1370, $1277,922,709 \mathrm{~cm}^{-1} .{ }^{1} \mathrm{H}-\mathrm{NMR}$ (DMSO-d $\left.{ }_{6}\right) \delta: 7.42-8.12$ (10H, aromatic), $13.15(2 \mathrm{H}, \mathrm{OH}) \mathrm{ppm}$.

\section{Polymer synthesis}

Into a $100 \mathrm{~mL}$ round bottomed flask were placed a mixture of $\mathrm{N}$-pyrromellitimido-4-amino benzoic acid 3 (0.72 g, $1.57 \mathrm{mmol})$, 4,4'-diamino diphenyl sulfone 4 (0.39 g, $1.57 \mathrm{mmol})$, calcium chloride $(0.60 \mathrm{~g})$, triphenyl phosphite $(1.00 \mathrm{~mL})$, pyridine $(1.00 \mathrm{~mL})$ and $\mathrm{N}$-methyl-2pyrrolidone $(4.00 \mathrm{~mL})$. The mixture was heated for $1 \mathrm{~h}$ at $60{ }^{\circ} \mathrm{C}, 2 \mathrm{~h}$ at $90{ }^{\circ} \mathrm{C}$ and then refluxed at $140{ }^{\circ} \mathrm{C}$ for $9 \mathrm{~h}$ until a viscous solution was formed. Then it was cooled to room temperature and $30 \mathrm{~mL}$ of methanol was added to reaction mixture. The precipitate was formed, filtered off and washed with methanol. The resulting polymers 5 were dried under vacuum to leave $0.93 \mathrm{~g}$ (90\%). FT-IR (KBr): 3415, 3190-3065, 1774, 1718, 1664, 1587, 1503, 1369, 1318, 1144, 1101, $708 \mathrm{~cm}^{-1}$. Elemental analysis for $\mathrm{C}_{36} \mathrm{H}_{20} \mathrm{~N}_{4} \mathrm{O}_{8} \mathrm{~S}$, calculated; C, 64.7; H, 3.0; N, 8.4; found; C, $65.5, \mathrm{H}, 3.0 ; \mathrm{N}, 9.1$.

\section{PAI-nanocomposite synthesis $\mathbf{5 a}$ and $\mathbf{5 b}$}

PAI-nanocomposites $\mathbf{5 a}$ and $\mathbf{5 b}$ were produced by solution intercalation method, in two different amounts of organoclay particles (10 and $20 \mathrm{wt} . \%)$ were mixed with appropriate amounts of PAI $(0.50 \mathrm{~g}, 0.74 \mathrm{mmol})$ solution in NMP $(8.00 \mathrm{~mL})$ to yield particular nanocomposite concentrations. To control the dispersibility of organoclay in PAI matrix, 
constant stirring was applied at $25{ }^{\circ} \mathrm{C}$ for $24 \mathrm{~h}$. Nanocomposite films were cast by pouring the solutions for each concentration into Petri dishes placed on a labelled surface followed by the evaporation of solvent at $70{ }^{\circ} \mathrm{C}$ for $12 \mathrm{~h}$. Films were dried at $80{ }^{\circ} \mathrm{C}$ under vacuum to a constant weight. FT-IR(KBr) for PAI-nanocomposites 5a: 3435, 3190, 1775, 1719, 1660, 1587, 1503, 1369, 1318, 1144, 1100, 1041, 754, $511 \mathrm{~cm}^{-1}$. FT-IR (KBr) for PAI-nanocomposites 5b: 3440, $3165-3045,1775,1720,1661,1587,1503,1369,1318,1145,1101,1042,753,458 \mathrm{~cm}^{-1}$.

The water absorption analysis

The water absorption of PAI-nanocomposite films was carried out using a procedure under ASTM D570-81 [24]. The films were dried in a vacuum oven at $80{ }^{\circ} \mathrm{C}$ to a constant weight and then weighed to get the initial weight $\left(\mathrm{W}_{\mathrm{o}}\right)$. The dried films were immersed in deionized water at $25{ }^{\circ} \mathrm{C}$. After $24 \mathrm{~h}$, the films were removed from water and then they were quickly placed between sheets of filter paper to remove the excess water and films were weighed immediately. The films were again soaked in water. After another $24 \mathrm{~h}$ soaking period, the films were taken out, dried and weighed for any weight gain. This process was repeated again and again till the films almost attained the constant weight. The total soaking time was $168 \mathrm{~h}$ and the samples were weighed at regular $24 \mathrm{~h}$ time intervals to get the final weight $\left(\mathrm{W}_{\mathrm{f}}\right)$. The percent increase in weight of the samples was calculated by using the formula $\left(\mathrm{W}_{\mathrm{f}}-\mathrm{W}_{\mathrm{o}}\right) / \mathrm{W}_{\mathrm{o}}$.

\section{RESULTS AND DISCUSSION}

\section{Monomer synthesis}

bis(4-Carboxyphenyl)-N,N'-pyromellitimide acid $\mathbf{3}$ was synthesized by the condensation reaction of one equimolar of pyromellitic dianhydride $\mathbf{1}$ with two equimolar of $p$-amino benzoic acid $\mathbf{2}$ in a mixture of acetic acid solution and pyridine (Scheme 1).<smiles>CC(C)(C)[C@@H](C(=O)O)c1ccc(-n2c(=O)c3cc4c(=O)n(-c5ccc(C(=O)O)cc5)c(=O)c4cc3c2=O)cc1</smiles>
(1) (2)

(3)

Scheme 1. Synthetic route of bis(4-carboxyphenyl)-N,N'-pyromellitimide acid $\mathbf{3}$.

The chemical structure of diacid $\mathbf{3}$ was confirmed by FT-IR and ${ }^{1} \mathrm{H}-\mathrm{NMR}$ spectroscopy. In the FT-IR spectrum of diacid 3 peaks appearing at $3500-2500 \mathrm{~cm}^{-1}$ (acid O-H stretching), 1778 $\mathrm{cm}^{-1}$ ( $\mathrm{C}=\mathrm{O}$ asymmetric imide stretching), $1722 \mathrm{~cm}^{-1}$ ( $\mathrm{C}=\mathrm{O}$ acid and symmetric imide stretching), $1422-1370$ and $709 \mathrm{~cm}^{-1}$ (imide characteristic ring vibration) confirmed the presence of imide ring and carboxylic groups in this compound (Figure 1). The ${ }^{1} \mathrm{H}-\mathrm{NMR}$ spectrum of diacid 3 shows peaks between $\delta=7.42-8.12 \mathrm{ppm}$ related to aromatic protons and a broad peak at $\delta=$ $13.15 \mathrm{ppm}$ was assigned for protons of the $\mathrm{COOH}$ groups (Figure 2).

Polymer synthesis

PAI 5 was synthesized by the direct solution polycondensation reaction of an equimolar mixture of diacide $\mathbf{3}$, an equimolar mixture of diamine $\mathbf{4}$ with triphenyl phosphite, NMP, calcium chloride and pyridine as condensing agents (Scheme 2). 
The entire polycondensation readily proceeded in a homogeneous solution. Tough and stringy precipitate formed when the viscous PAI solution was obtained in good yield (90\%).

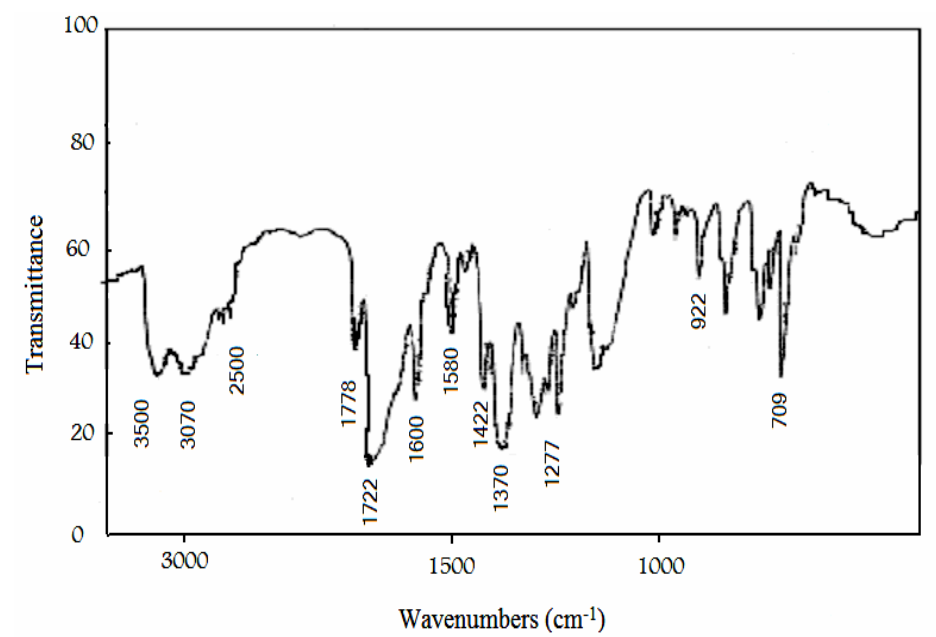

Figure 1. FT-IR spectrum of diacid 3.

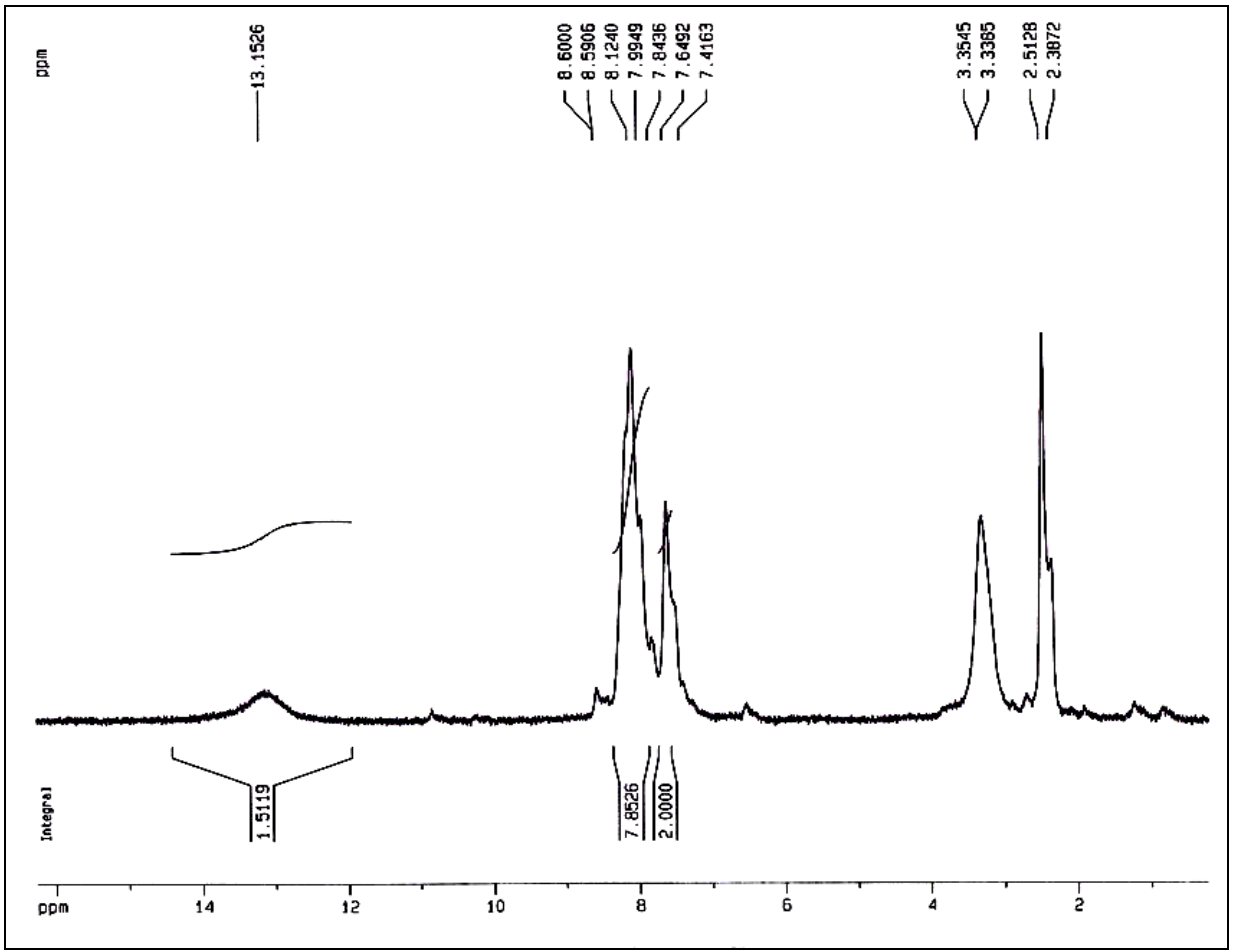

Figure 2. ${ }^{1} \mathrm{H}-\mathrm{NMR}$ spectrum of diacid $\mathbf{3}$.

Bull. Chem. Soc. Ethiop. 2013, 27(1) 

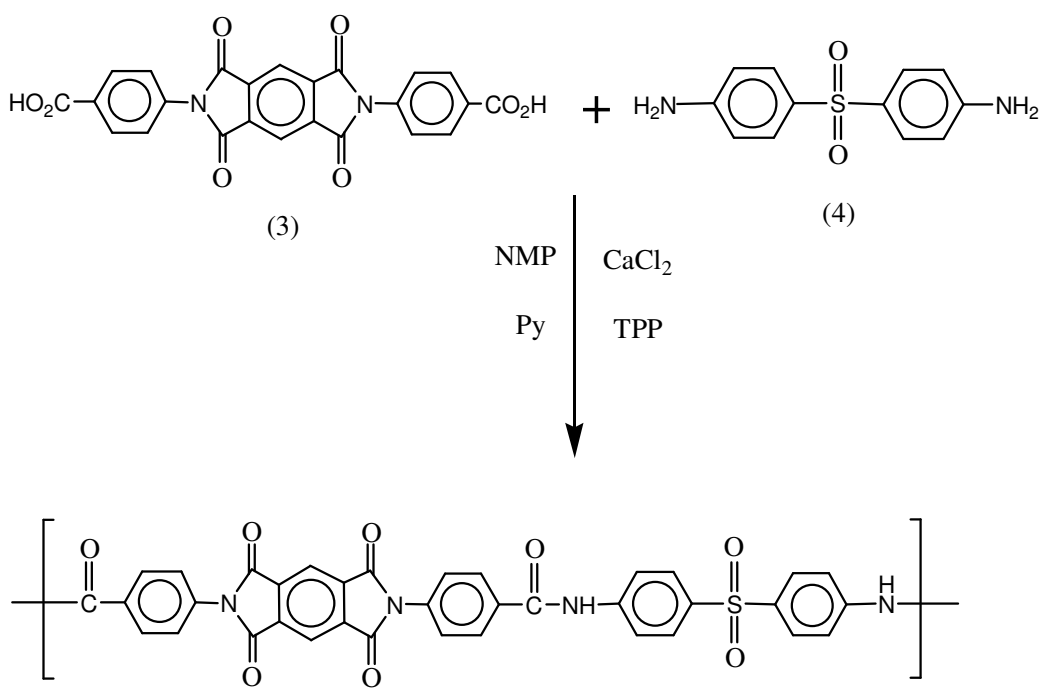

(5)

Scheme 2. Synthetic route of poly(amide-imide) 5 .

\section{Polymer characterization}

This polymer had inherent viscositiy of $0.29 \mathrm{dL} / \mathrm{g}$ (Measured at a concentration of $0.5 \mathrm{~g} \mathrm{dL}^{-1}$ in DMF at $25^{\circ} \mathrm{C}$ ) and was confirmed as PAI by using FT-IR spectroscopy and elemental analysis. A representative FT-IR spectrum of PAI 5 is shown in (Figure 3). PAI 5 had absorption bands between $1774 \mathrm{~cm}^{-1}$ and $1664 \mathrm{~cm}^{1}$ due to imide and amide carbonyl groups. Absorption bands around 1369-1318 $\mathrm{cm}^{-1}$ and $732 \mathrm{~cm}^{-1}$ demonstrated the presence of the imide heterocyclic ring in this polymer. Also absorption band of amide group appeared at $3415 \mathrm{~cm}^{-1}(\mathrm{~N}-\mathrm{H}$ stretching). The elemental analysis value of the resulting polymer was in good agreement with the calculated values for the proposed structure.

The solubility of PAI 5 was investigated with $0.01 \mathrm{~g}$ polymeric sample in $2 \mathrm{~mL}$ of solvent. PAI (5) was dissolved in organic solvent such as DMF, DMSO and NMP at room temperature and it was insoluble in solvents such as chloroform, methylene chloride, methanol, ethanol and water.

\section{PAI-nanocomposite films}

PAI-nanocomposite films were transparent and yellowish brown in color. The incorporation of organoclay changed the color of films to dark yellowish brown. Moreover, a decrease in the transparency was observed at higher clay contents. (Scheme 3) show the flow sheet diagram and synthetic scheme for PAI-nanocomposite films $\mathbf{5 a}$ and $\mathbf{5} \mathbf{b}$.

The chemical structure of PAI-nanocomposite films $\mathbf{5 a}$ and $\mathbf{5 b}$ were determined by using FT-IR, X-ray diffraction (XRD) and Scanning electron microscopy (SEM) techniques.

FT-IR spectra of PAI-nanocomposite films $\mathbf{5 a}$ and $\mathbf{5 b}$ showed the characteristic absorption bands of the $\mathrm{Si}-\mathrm{O}$ and $\mathrm{Mg}-\mathrm{O}$ moieties at 1041,511 and $465 \mathrm{~cm}^{-1}$, respectively. The incorporation of organic groups in PAI-nanocomposite films were confirmed by the presence of peaks at 1775, 1719, 1369, 754 (imide rings) and 1660, 1318 (amide groups) (Figure 4). 


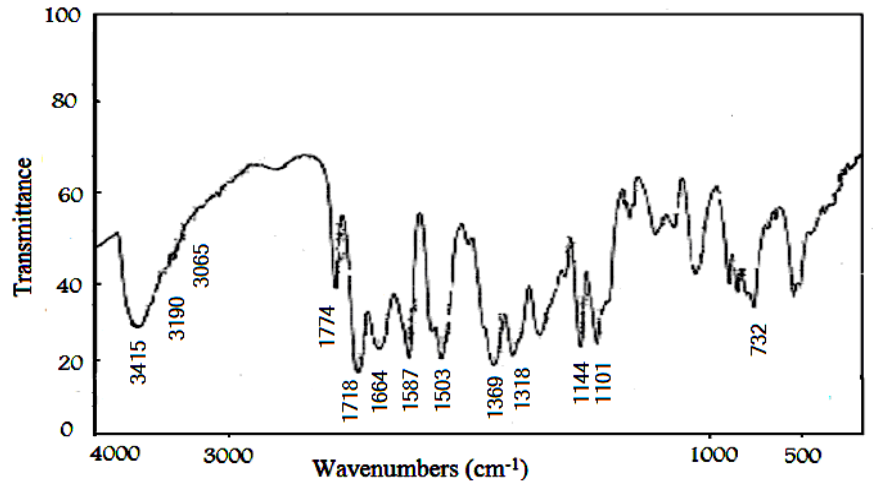

Figure 3. FT-IR spectrum of PAI 5.

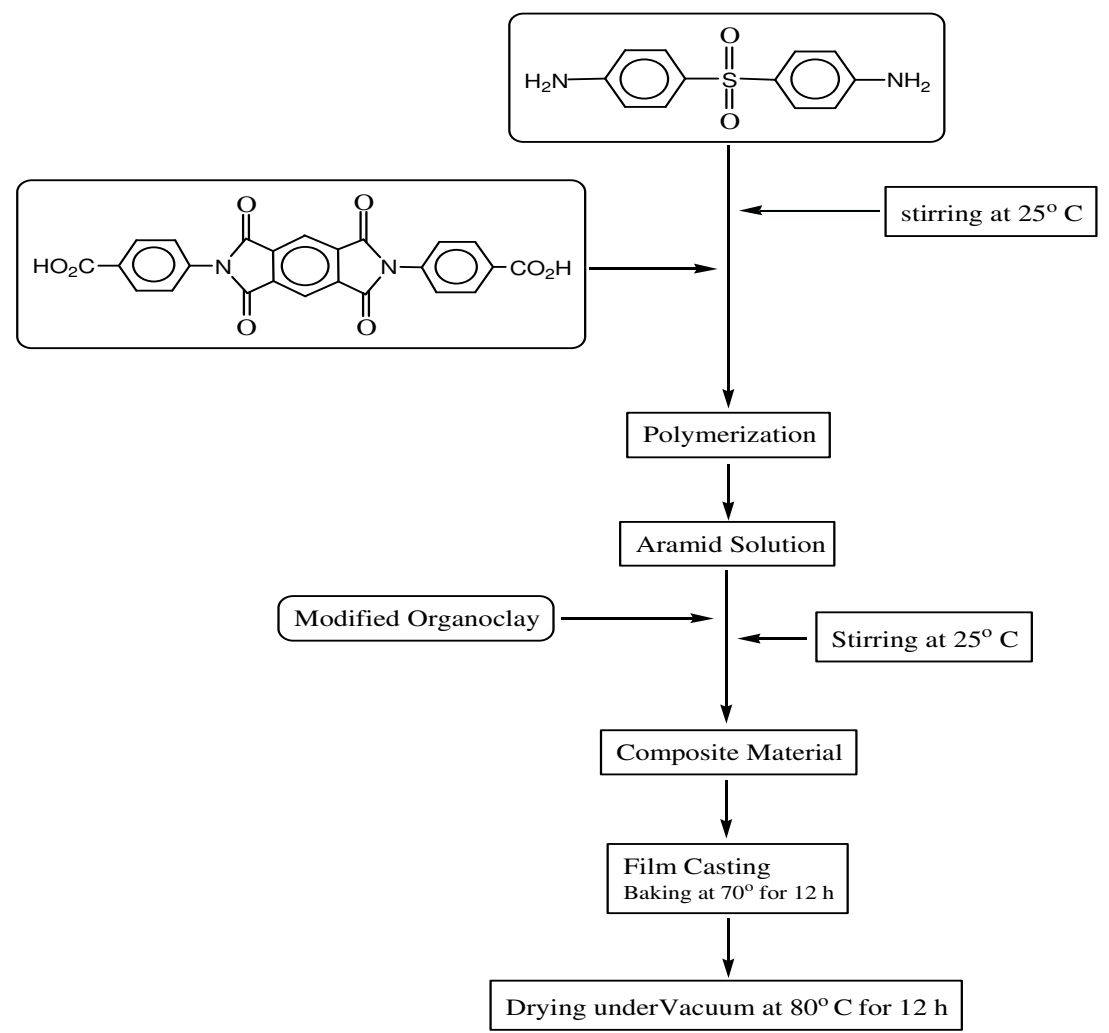

Scheme 3. Flow sheet diagram for the synthesis of PAI-nanocomposites film $\mathbf{5 a}$ and $\mathbf{5 b}$. 

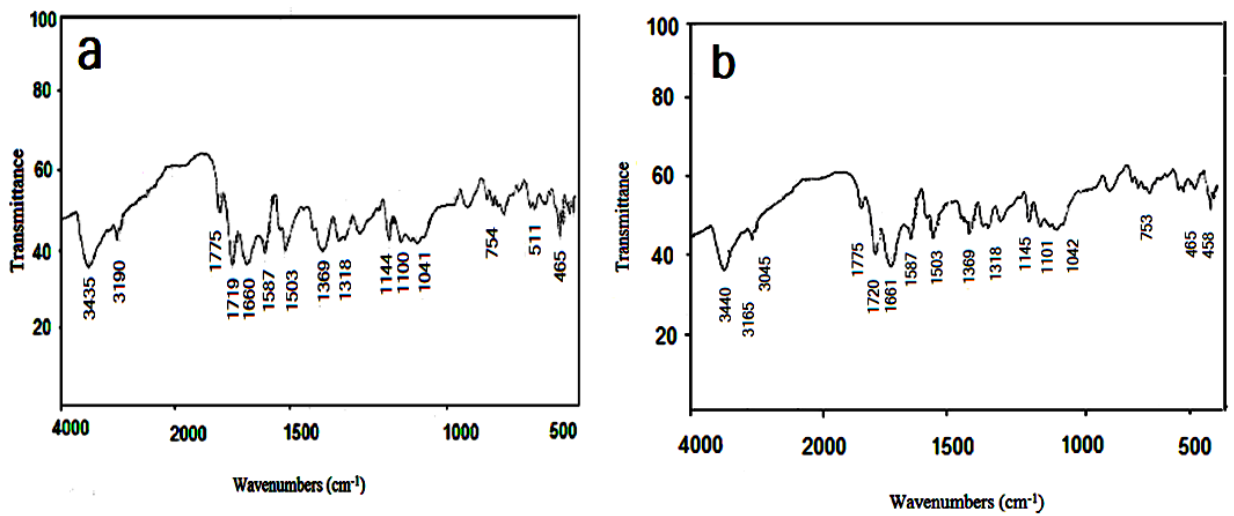

Figure 4. FTIR spectra of PAI-nanocomposite films $\mathbf{5 a}(\mathrm{a})$ and $\mathbf{5 b}(\mathrm{b})$.

Figure 5 shows the XRD patterns of PAI-nanocomposite films $\mathbf{5 a}$ and $\mathbf{5 b}$ containing 10 and 20 wt. $\%$ of silicate particles. The result reveals an increased d-spacing from $1.00 \mathrm{~nm}\left(8.93^{\circ}\right)$ of Na-MMT to $1.49 \mathrm{~nm}\left(5.15^{\circ}\right)$ of PAI-nanocomposite film $(10 \mathrm{wt} . \%)$ and $\left(4.23^{\circ}\right)$ of PAInanocomposite film $(20 \mathrm{wt} . \%)$. These results indicated significant expansion of the silicate layer after insertion to PAI chains. The shift in the diffraction peaks PAI-nanocomposite films confirms that intercalation has been taken place. This is direct evidence that PAInanocomposites have been formed as the nature of intercalating agent also affects the organoclay dispersion in the polymer matrix. Usually there are two types of nanocomposites depending upon the dispersion of clay particles. The first type is an intercalated polymer clay nanocomposite, which consists of well ordered multi layers of polymer chain and silicate layers a few nanometers thick. The second type is an exfoliated polymer-clay nanocomposite, in which is there is a loss of ordered structures due to the extensive penetration of polymer chain into the layer silicate. Such part would not produce distinct peaks in the XRD pattern [25]. In our PAInanocomposite films there are coherent XRD signal at $5.15^{\circ}$ and $4.23^{\circ}$ related to 10 and 20 wt.\% nanocomposite films, respectively.
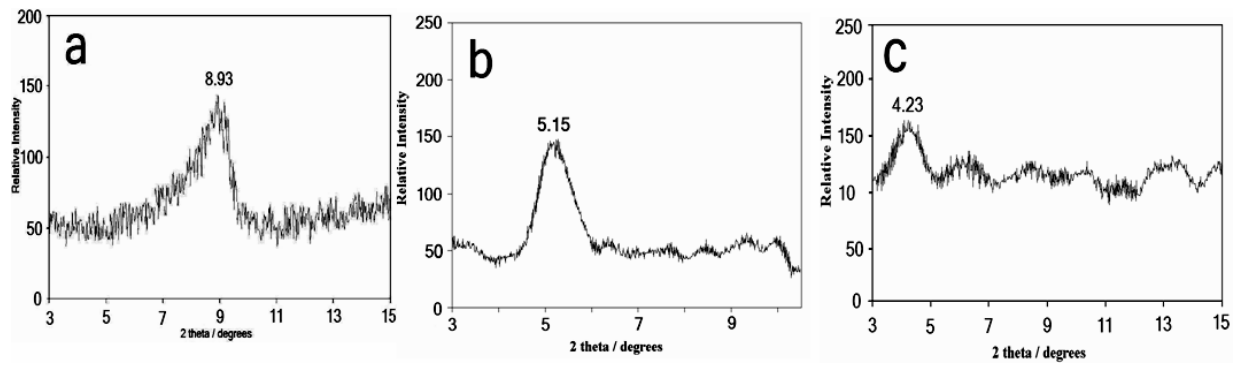

Figure 5. X-ray diffraction patterns of organoclay (a), PAI-nanocomposite films $\mathbf{5 a}$ (b) and $\mathbf{5 b}$ (c).

The surface morphology of the PAI-nanocomposite films prepared by solution intercalation technique is compared by SEM analyses. (Figure 6) show the morphological images of 10 and 20 wt.\% nanocomposite films, respectively. The SEM images show that PAI matrix has a smooth morphology, where as the PAI matrix has an amorphous morphology. Also SEM micrographs of PAI-nanocomposite containing 10 and $20 \mathrm{wt}$ \% clay platelets were uniformly distributed without agglomeration.

Bull. Chem. Soc. Ethiop. 2013, 27(1) 

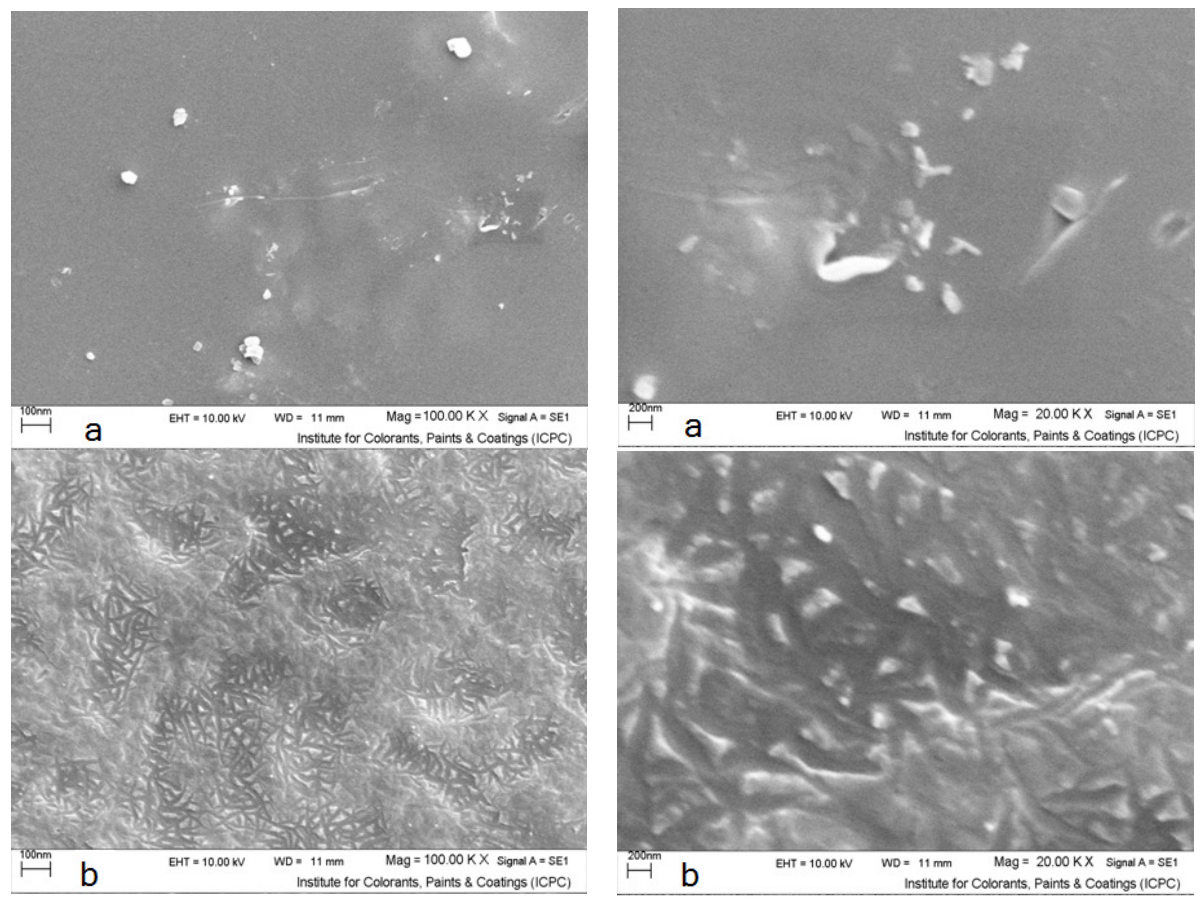

Figure 6. Scanning electron micrographs of PAI-nanocomposite films $\mathbf{5 a}(a)$ and $\mathbf{5 b}(\mathbf{b})$.

Comparing of thermal gravimetry analysis, optical clarity and water absorption between PAI and PAI-nanocomposite films

\section{Optical clarity}

Optical clarity of PAI-nanocomposite films containing 10 and $20 \mathrm{wt} \%$ clay platelets and neat PAI were compared by UV-Vis spectroscopy in the region of 300-800 $\mathrm{nm}$. (Figure 7) show the UV-Vis transmission spectrum of pure PAI and PAI-nanocomposite films containing 10 and 20 wt. \% clay platelets. This spectrum show that the UV-Vis region $(300-800 \mathrm{~nm})$ is affected by the presence of the clay particles and exhibiting low transparency reflected to the primarily intercalated composites. Results show that the optical clarity of PAI-nanocomposite films system is significantly lower than the neat PAI system.

\section{Thermal gravimetry analysis}

The thermal properties of PAI-nanocomposite films containing 10 and $20 \mathrm{wt} . \%$ clay platelets and neat PAI were investigated by using TGA and DSC in nitrogen atmosphere at a rate of heating of $10{ }^{\circ} \mathrm{C} / \mathrm{min}$, and thermal data are summarized in (Table 2). These samples exhibited good resistance to thermal decomposition, up to $145-180{ }^{\circ} \mathrm{C}$ in nitrogen, and began to decompose gradually above this temperature. $\mathrm{T}_{5}$ for these samples ranged from $145-180{ }^{\circ} \mathrm{C}$ and $\mathrm{T}_{10}$ for them ranged from $175-220{ }^{\circ} \mathrm{C}$, and residual weights at $600{ }^{\circ} \mathrm{C}$ ranged from 50.07 $55.72 \%$ in nitrogen. Incorporation of organoclay into the PAI matrix also enhanced the thermal stability of the nanocomposites. Figure 8 shows the TGA thermograms of PAI-nanocomposites 
under nitrogen atmosphere. Thus, we can speculate that interacting PAI chains between the clay layers serve to improve the thermal stability of nanocomposites. The addition of organoclay in polymeric matrix can significantly improve the thermal stability of PAI.

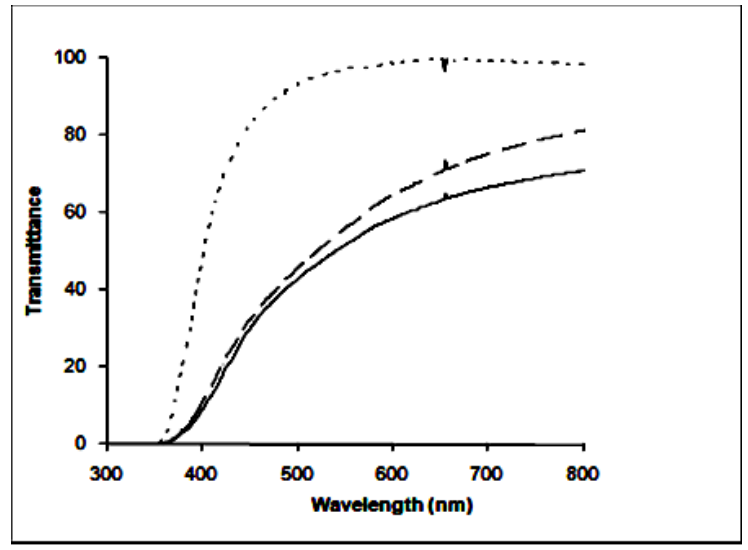

Figure 7. UV-Vis spectrum of PAI 5 …., PAI-nanocomposite films $\mathbf{5 a}-\mathbf{-}$ and $\mathbf{5 b}-$.

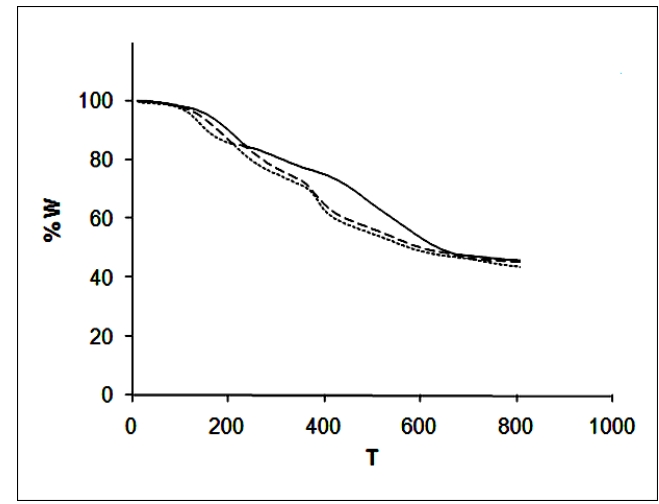

Figure 8. TGA spectrum of PAI 5 ….., PAI-nanocomposite films $\mathbf{5} \mathbf{a}-\mathbf{-}$ and $\mathbf{5 b}-$.

\section{Water absorption}

The PAI under investigation contains polar and cyclic imide rings and also polar amide groups in the backbone that have the tendency to uptake water through hydrogen bonding. Thus water absorption measurements become necessary for neat PAI 5 and PAI-nanocomposite films $\mathbf{5 a}$ and $\mathbf{5 b}$ and data are shown in (Table 1). In the water permeability studies, we found that the incorporation of clay platelets into PAI matrix results in a decrease of water uptake relative to pure PAI by forming the tortuous path of water permeant. Water permeability depends on length, orientation and degree of delamination of layered silicate. It should be noted that a further increase in clay concentration resulted in an enhanced barrier property of nanocomposites which may be attributed to the plate-like clays that effectively increase the length of the diffusion pathways, as well as decrease the water permeability.

Bull. Chem. Soc. Ethiop. 2013, 27(1) 
Table 1. Thermal behaviors and water uptake of neat PAI (5) and PAI-nanocomposite films $\mathbf{5} \mathbf{a}$ and $\mathbf{5 b}$.

\begin{tabular}{|c|c|c|c|c|}
\hline Sample & $\mathrm{T}_{5}\left({ }^{\circ} \mathrm{C}\right)^{\mathrm{a}}$ & $\mathrm{T}_{10}\left({ }^{\mathrm{o}} \mathrm{C}\right)^{\mathrm{b}}$ & Char Yield $^{\mathrm{c}}$ & ${\text { Water uptake }(\%)^{\mathrm{d}}}^{\mathrm{b}}$ \\
\hline $\mathbf{5}$ & 144 & 174 & 50.0 & 4.17 \\
\hline $\mathbf{5 a}$ & 160 & 198 & 51.3 & 1.81 \\
\hline $\mathbf{5 b}$ & 179 & 220 & 55.7 & 0.22 \\
\hline
\end{tabular}

${ }^{\mathrm{a}, \mathrm{b}}$ Temperature at which $5 \%$ and $10 \%$ weight loss was recorded by TGA at heating rate of $10{ }^{\circ} \mathrm{C} / \mathrm{min}$ in $\mathrm{N}_{2}$, respectively ${ }^{\mathrm{d}}$ Percentage weight of material left undecomposed after TGA analysis $800{ }^{\circ} \mathrm{C}$.

\section{CONCLUSION}

The PAI-nanocomposites were successfully prepared using solution intercalation method. The structure and the uniform dispersion of organoclay throughout the PAI matrix were confirmed by FT-IR, XRD and SEM analyses. The optical clarity and water absorption property of PAInanocomposites were decreased significantly with increasing the organoclay contents in PAI matrix. On the contrary the thermal stability of PAI-nanocomposites were increased significantly with increasing the organoclay contents in PAI matrix. The enhancements in the thermal stability of the nanocomposites films $\mathbf{5 a}$ and $\mathbf{5 b}$ by introducing organoclay may be due to the strong interactions between polymeric matrix and organoclay, as well as intercalation and dispersion of clay platelets in the PAI matrix.

\section{REFERENCES}

1. Giannelis, E.P. Adv. Mater. 1996, 8, 29.

2. Yano, Y.; Usuki, A.; Kurauchi, T.; Kamingato, O. J. Polym. Sci. Part A: Polym. Chem. 1993, 31, 2493.

3. Zulfiqar, S.; Ahmad, Z.; Ishhagh, M.; Saeed, S.; Sarwar, M.I. J. Mater. Sci. 2007, 42, 93.

4. Sikka, M.; Cerini, L.N.; Ghosh, S.S.; Wieny, K.I. J. Polym. Sci. Part B: Polym. Phys. 1996, 34, 1443.

5. Xu, R.; Manias, E.; Snyder, A. J.; Runt, J. Macromolecules 2001, 34, 337.

6. Kausar, A.; Zulfiqar, S.; Shabbir, S.; Ishagh, M.; Sarwar, M.I. Polym. Bull. 2007, 59, 457.

7. Bibi, N.; Sarwar, M.I.; Ishagh, M.; Ahmad, Z. Polym. Polym. Compos. 2007, 15, 313.

8. Zulfiqar, S.; Sarwar, M. I. Scr. Mater. 2008, 59, 436.

9. Fornes, T.D.; Yoon, P.J.; Hunter, D.L.; Keskkula, H.; Paul, D.R. Polymer 2002, 43, 5915.

10. Chen, G.M.; Ma, Y.M.; Qi, Z.N. J. Appl. Polym. Sci. 2000, 77, 2201.

11. Yano, Y.; Usukia, A.; Kurauchi, T.; Kamigato, O. J. Polym. Sci. Part A: Polym. Chem. 1993, 31, 2493.

12. Ghosh, M. K.; Mittal, K.L. Polyimide: Fundamental and Applications, Dekker: New York; 1996.

13. Liaw, D.J.; Liaw, B.Y.; Polymer 2001, 42, 839.

14. Zhang, Q.; Li, S.; Li, W.; Zhang, S. Polymer 2007, 48, 6246.

15. Zhang, Q.; Chen, S. Polymer 2007, 48, 2250.

16. Saxena, A.; Rao, V.L.; Prabhakaran, P.V.; Nianan, K.N. Eur. Polym. J. 2003, 39, 401.

17. Yang, C.P.; Chen, Y.P.; Woo, E.M. Polymer 2004, 45, 5279.

18. Liaw, D.J.; Chen, W.H. Polym. Degrad. Stab. 2006, 91, 1731.

19. Mallakpour, S.; Kolahdoozan, M. J. Appl. Polym. Sci. 2007, 104, 1248.

20. Faghihi, Kh.; Naghavi, H. J. Appl. Polym. Sci. 2005, 96, 1776.

21. Faghihi, Kh.; Mozafari, Z. Turk. J. Chem. 2008, 32, 673.

22. Mallakpour, S.; Hajipour, A.R.; Habibi, S. J. Appl. Polym. Sci. 2001, 80, 1312.

23. Zulfiqar, S.; Sarwar, M.I. J. Incl. Phenom. Macrocycl. Chem. 2008, 62, 353.

24. Krishnan, P.S.G.; Wisanto, A.E.; Osiyemi, S.; Ling, C. Polym. Inter. 2007, 56, 787.

25. Bharadwaj, R.K. Macromolecules 2001, 34, 9189. 